\title{
Residual Brewing Yeast as Substrate for Co-Production of Cell Biomass and Biofilm Using Candida maltosa SM4
}

\author{
Vidal Flores-Copa ${ }^{1,+}{ }^{+}$Luis Romero-Soto ${ }^{1,2,+}{ }^{\oplus}$, Danitza Romero-Calle ${ }^{3}$, María Teresa Alvarez-Aliaga ${ }^{3}$, \\ Felipe Orozco-Gutierrez ${ }^{4}$, José Vega-Baudrit ${ }^{4}\left(\mathbb{D}\right.$, Carlos Martín ${ }^{5, *}$ (i) and Cristhian Carrasco ${ }^{1, *}$ (D) \\ 1 Instituto de Investigación y Desarrollo de Procesos Químicos, Chemical Engineering, Faculty of Engineering, \\ Universidad Mayor de San Andrés, La Paz P.O. Box 12958, Bolivia; sayabeer.vidal@gmail.com (V.F.-C.); \\ lars.biotec@gmail.com or luis_alejandro.romero_soto@biotek.lu.se (L.R.-S.) \\ 2 Division of Biotechnology, Lund University, SE-221 00 Lund, Sweden \\ 3 Instituto de Investigaciones Fármaco Bioquímicas, Facultad de Ciencias Farmacéuticas y Bioquímicas, \\ Universidad Mayor de San Andrés, La Paz P.O. Box 3239, Bolivia; danitzaxiomara@gmail.com (D.R.-C.); \\ mariateresa.alvarezaliaga@gmail.com (M.T.A.-A.) \\ 4 National Nanotechnology Laboratory, National Center for High Technology, San José 10109, Costa Rica; \\ felipeorozcogutierrez@gmail.com (F.O.-G.); jvegab@gmail.com (J.V.-B.) \\ 5 Department of Chemistry, Umeå University, SE-901 87 Umeå, Sweden \\ * Correspondence: carlos.martin@umu.se (C.M.); cristhian.carrasco@gmail.com (C.C.) \\ $+\quad$ First authorship shared by V.F.-C. and L.R.-S.
}

Citation: Flores-Copa, V.;

Romero-Soto, L.; Romero-Calle, D.; Alvarez-Aliaga, M.T;;

Orozco-Gutierrez, F.; Vega-Baudrit, J.;

Martín, C.; Carrasco, C. Residual

Brewing Yeast as Substrate for

Co-Production of Cell Biomass and Biofilm Using Candida maltosa SM4.

Fermentation 2021, 7, 84.

https://doi.org/10.3390/

fermentation7020084

Academic Editor: Diomi Mamma

Received: 5 May 2021

Accepted: 26 May 2021

Published: 30 May 2021

Publisher's Note: MDPI stays neutral with regard to jurisdictional claims in published maps and institutional affiliations.

Copyright: (c) 2021 by the authors. Licensee MDPI, Basel, Switzerland. This article is an open access article distributed under the terms and conditions of the Creative Commons Attribution (CC BY) license (https:// creativecommons.org/licenses/by/ $4.0 /)$.

\begin{abstract}
Candida maltosa was cultivated in the liquid phase of residual brewing yeast, a major brewery residue, to produce biomass and biofilm. Using response surface methodology, the effect of two variables at two different levels was investigated. The independent variables were agitation speed (at 100 and $200 \mathrm{rpm}$ ), and aeration (at 1 and $3 \mathrm{~L} \mathrm{~min}^{-1}$ ). Aeration was identified to be important for the production of both biomass and biofilm, while agitation was the only factor significantly affecting biofilm production. The maximal production of biofilm $\left(2.33 \mathrm{~g} \mathrm{~L}^{-1}\right)$ was achieved for agitation of $200 \mathrm{rpm}$ and aeration of $1 \mathrm{~L} \mathrm{~min}^{-1}$, while the maximum for biomass $\left(16.97 \mathrm{~g} \mathrm{~L}^{-1}\right)$ was reached for $100 \mathrm{rpm}$ agitation and $3 \mathrm{~L} \mathrm{~min}^{-1}$ air flow. A logistic model applied to predict the growth of C. maltosa in the exponential phase and the biofilm production, showed a high degree of agreement between the prediction and the actual biomass measured experimentally. The produced biofilms were further characterized using Fourier-transform infrared spectroscopy (FTIR), Scanning Electron Microscopy (SEM) and Thermogravimetric Analysis (TGA). FTIR allowed the identification of methyl, carbonyl ester and sulfate groups, and revealed the presence of uronic acid moieties and glycosidic bonds. Water-retention ability up to relatively high temperatures was revealed by TGA, and that makes the produced biofilm suitable for production of hydrogels. SEM also gave indications on the hydrogel-forming potential of the biofilm.
\end{abstract}

Keywords: biomass production; Candida maltosa; biofilm production; brewery residues; co-production

\section{Introduction}

The scarcity of high-quality food is one of the most acute problems of human civilization and exploring new food sources is an urgent requirement for fulfilling the "zero hunger" Sustainable Development Goal [1]. Protein is an important component of the human diet but reaching the requirements of the increasing world population can cause disproportionate growth of meat and dairy production or uncontrolled increase in land usage for producing leguminous seeds. Single Cell Protein (SCP), constituted by dried cells of microorganisms can safely be included in the human food chain [2] as a protein source of increasing relevance for developing healthier food with optimal amino acid composition. Inclusion of SCP in the human diet can contribute to satisfying our protein requirements without unsustainable expanding livestock production for animal protein or arable land for plant-based protein. SCP has been used as a food source for a long time, 
and its global consumption has increased notoriously during war periods for alleviating the scarcity of food. SCP has interesting advantages over other protein sources, and it can be obtained through microbial cultivations, with high productivities, and independence of seasonal factors from a wide variety of raw materials [3]. SCP can be produced even from hydrocarbon feedstocks. During the 1970s, production of so-called protein-vitamin concentrate using different yeast species of the Candida genus grown on biomass-based substrates and even on n-alkanes became a widely distributed industrial process in the Soviet Union and other East European countries [2].

Candida maltosa is a non-conventional yeast that can be used for SCP production. Due to its ability to grow on n-alkanes as the only carbon source [4], C. maltosa is used also in bioremediation processes [5], namely in biodegradation of oils in aqueous media [6,7]. An important feature of C. maltosa is its ability to produce exocellular polymers [8-10].

Microbial polymers have many uses [11,12], and their production from renewable sources has attracted a lot of attention linked to the need to design low-cost processes for efficient use of natural resources [13]. Biopolymers of biotechnological interest are often produced by bacteria, while those from yeasts are less studied mainly because of their low biosynthesis yield [14]. Pullulan, a linear glucan resulting from cultivation of the polymorphic fungus Aureobasidium pullulans, is one of the few largely commercialized polysaccharides produced by a member of Fungi kingdom [15]. New approaches, widening the substrate base and optimizing the operational conditions are required for increasing the competitiveness of biotechnological production of biopolymers by fungal cultivations using organisms such as the yeast C. maltosa.

Brewery residues constitute a major problem of the brewing business due to the large volumes that are generated on a daily basis [16]. Although the use of brewer's spent grain (BSG), the main brewery by-product, in animal feed [17,18] and other areas [19], is a well-investigated issue, a holistic approach to the exploitation of all residues of the brewing industry is still challenging, and production of high added-value products along with complementary techno-economic analysis is still in its early development [20,21]. Residual Brewing Yeast (RBY), the wet waste resulting after several recirculation cycles aimed at improved utilization of yeast and fermentable carbohydrates, is the second-largest byproduct from the brewing industry [22]. RBY contains significant residual carbohydrates (35-45\% dry biomass), proteins, amino acids, minerals, lipids and enzymes, as well as ethanol remains that are too expensive to separate and are discarded along with the rest of this residue.

Although the use of RBY in the animal feed sector or as a source of bioactive compounds, such as polyphenols and $\beta$-glucans, has been considered [22,23], using it for formulating substrates for biotechnological applications is also of high interest. The simultaneous production of valuable bio-products, such as yeast biomass and biofilm, is a process of interesting biotechnological perspectives for adding value to RBY. The fact that two different products are targeted, which is important for the economic feasibility [24,25], potentiates the industrial attractiveness of the proposed bioprocess.

This study is aimed at providing an economic use of RBY, which is currently underutilized or even disposed of, by using it as a substrate for C. maltosa cultivation for producing biofilm and cell biomass, two products with potential added-value use in the food, cosmetic and pharmaceutical industries.

\section{Materials and Methods}

\subsection{Microorganism Maintenance and Pre-Culture Conditions}

C. maltosa SM4 strain from the microbial culture collection of the Instituto de Investigaciones Fármaco Bioquímicas, Universidad Mayor de San Andrés (La Paz, Bolivia), was used in this study. It was maintained in solid YM agar containing (in grams per liter) yeast extract (3), malt extract (3), soy peptone (5), agar-agar (20) and glucose (10).

For the pre-culture, one colony was transferred to a sterile 7-mL tube with $2 \mathrm{~mL}$ of YM medium containing (in grams per liter) yeast extract (3), malt extract (3), soy peptone 
(5), glucose (10). The tube was then incubated for $24 \mathrm{~h}$ in an orbital shaker (WIS-30, witeg Labortechnik GmbH, Wertheim, Germany) at $30^{\circ} \mathrm{C}$ and $100 \mathrm{rpm}$.

\subsection{Conditioning of the Residual Brewing Yeast (RBY)}

The RBY used in the experiments was provided by Bebidas Independientes S.R.L. (La Paz, Bolivia). It was a wet slurry with a moisture content of $80.0 \pm 2.7 \%(w / w)$, composed to a large extend by residual biomass of brewer's yeast (Saccharomyces cerevisiae). The inactivation of residual S. cerevisiae was carried out at $90{ }^{\circ} \mathrm{C}$ for $3 \mathrm{~min}$, immediately after collecting the residue. After that, the material was stored at $4{ }^{\circ} \mathrm{C}$ in sterile flasks. Prior to its use, the residue was centrifuged at $3500 \mathrm{~g}$ for $10 \mathrm{~min}$, and the supernatant was collected and used for C. maltosa SM4 cultivation. RBY supernatant contained $23.8 \pm 0.6 \mathrm{~g} \mathrm{~L}^{-1}$ of protein, and it was composed primarily of the following residual carbon sources (in grams per liter): glucose (5), xylose (0.8), arabinose (0.7) and ethanol (16.9). The centrifugation pellet was discarded, but since it is a rather voluminous residue $(\sim 40 \%(w / w)$ of the initial material), future studies should include its upgrading and utilization. Since the pellet is rich in protein and other substances of biological value, possible application areas are (i) formulation of animal feed, and (ii) processing it to nutrient supplements as a substitute for commercial yeast extract for microbial cultivations.

\subsection{Microbial Acclimatization and Cultivation}

For acclimatization to the medium, C. maltosa SM4 pre-culture was inoculated in a $100-\mathrm{mL}$ sterile flask containing $37.5 \mathrm{~mL}$ of sterile conditioned RBY supernatant, and the culture mix was incubated at $30^{\circ} \mathrm{C}$ and $100 \mathrm{rpm}$ in an orbital shaker (WIS-30, witeg Labortechnik $\mathrm{GmbH}$, Wertheim, Germany) for approximately $24 \mathrm{~h}$ until the stationary phase of growth was reached, as previously described [9]. After that, $37 \mathrm{~mL}$ of the acclimatized C. maltosa SM4 pre-culture was inoculated in $760 \mathrm{~mL}$ of conditioned RBY supernatant in a 2.5-L bioreactor (Minifors, INFORS HT, Bottmingen, Switzerland), and the cultivation was run at $30{ }^{\circ} \mathrm{C}$ for $140 \mathrm{~h}$ under continuous aeration. The bioreactor was equipped with a one-paddle stirring system that ensured a stable and well-controllable mixing. Air was fed to the medium via a sparger mounted in the bottom of the vessel, and the inlet air supply was controlled with a mass flow controller. A $2^{2}$-factorial experimental design was performed using the agitation speed (at either 100 or $200 \mathrm{rpm}$ ) and the aeration (at either 1 or $3 \mathrm{~L} \mathrm{~min}^{-1}$ ) as independent factors. Triplicate trials were run for each experimental condition. Samples were taken periodically in pre-weighed 1.5-mL Eppendorf microtubes, and immediately placed in an ice bath. Details on the experimental results are provided in Table 1 and Figure 1. All transfer operations were carried out in a sterile laminar flow chamber (HFsafe-1200, Heal Force, Hong Kong, China).

Table 1. Summary of results from the cultivation of C. maltosa SM4 in RBY. Mean values of triplicate experiments and standard deviations are presented.

\begin{tabular}{|c|c|c|c|c|c|c|}
\hline $\begin{array}{l}\text { Agitation } \\
(\mathrm{rpm})\end{array}$ & $\begin{array}{l}\text { Aeration } \\
\left(\mathrm{L} \mathrm{min}^{-1}\right)\end{array}$ & $\begin{array}{l}\text { Biofilm } \\
\left(\mathrm{g} \mathrm{L} \mathrm{L}^{-1}\right)\end{array}$ & $\begin{array}{c}\mu^{\mathrm{a}} \\
\left(h^{-1}\right)\end{array}$ & $\begin{array}{c}\text { Biomass } \\
\text { Productivity } \\
\text { b } \\
\left(\mathrm{g} \mathrm{L}^{-1} \cdot \mathrm{h}^{-1}\right)\end{array}$ & $\begin{array}{c}Y_{s x}{ }^{\mathrm{c}} \\
\left(\mathrm{g} \mathrm{g}^{-1}\right)\end{array}$ & $\begin{array}{c}\text { Biomass } \\
\text { (g CDW } \\
\left.\mathrm{L}^{-1}\right)\end{array}$ \\
\hline 100 & 1 & $1.87 \pm 0.04$ & $0.027 \pm 0.005$ & $0.14 \pm 0.03$ & $0.44 \pm 0.02$ & $\begin{array}{c}14.17 \pm \\
1.47\end{array}$ \\
\hline 200 & 1 & $2.33 \pm 0.04$ & $0.057 \pm 0.011$ & $0.20 \pm 0.01$ & $0.41 \pm 0.02$ & $\begin{array}{c}13.17 \pm \\
0.61\end{array}$ \\
\hline 100 & 3 & $2.20 \pm 0.03$ & $0.080 \pm 0.008$ & $0.31 \pm 0.02$ & $0.53 \pm 0.01$ & $\begin{array}{c}16.97 \pm \\
2.01\end{array}$ \\
\hline 200 & 3 & $2.12 \pm 0.07$ & $0.067 \pm 0.009$ & $0.34 \pm 0.03$ & $0.48 \pm 0.02$ & $\begin{array}{c}15.47 \pm \\
3.10\end{array}$ \\
\hline
\end{tabular}

${ }^{a}$ Growth rate; ${ }^{b}$ Productivity was calculated as indicated by Shuler et al. [26]; ${ }^{c}$ Biomass yield. 


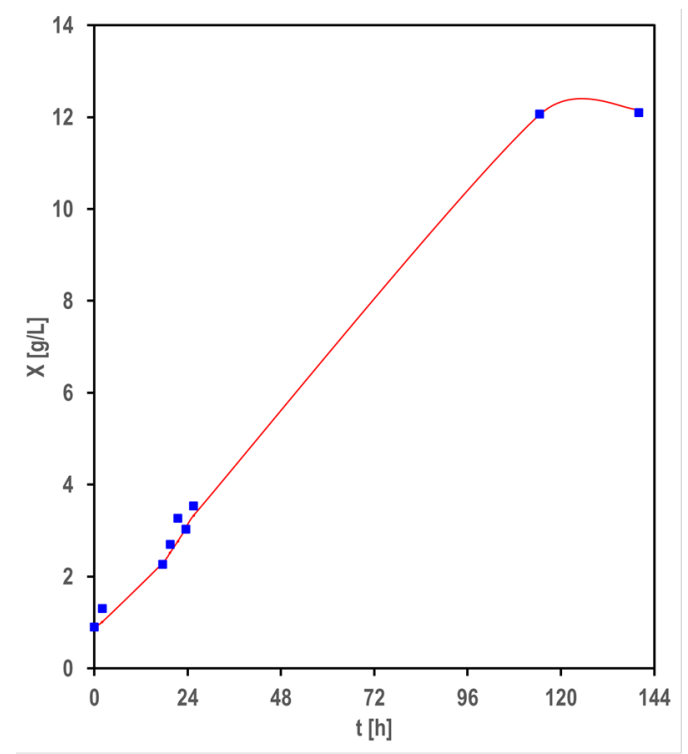

Figure 1. Growth kinetics of C. maltosa SM4 on RBY for $200 \mathrm{rpm}, 1 \mathrm{~L} \mathrm{~min}{ }^{-1}$. Biomass production actually achieved in the experiments ( $\square$ ) and predicted by the logistic model (-).

\subsection{Logistic Approach for the Modeling of the Cell Growth}

Diverse kinetic models have been proposed to describe growth kinetics, such as the equations of Monod and Luedeking-Piret, but logistic models are commonly used for fermentative processes [27,28]. Logistic models are sets of equations, where microbial growth is characterized in terms of loading capacity [28]. This is based on the dependence of specific growth rate $(\mu)$ on the unused loading capacity (Equation (1)) [26]:

$$
\mu=k\left(1-\frac{X}{X_{\infty}}\right)
$$

where $k$ is the growth rate, $X$ is the biomass at a certain time, and $X_{\infty}$ is the loading (or carrying) capacity.

Considering that exponential growth rate is a first-order differential equation (Equation (2)):

$$
\frac{d X}{d t}=\mu X
$$

We find:

$$
\frac{d X}{d t}=k X\left(1-\frac{X}{X_{\infty}}\right)
$$

Integrating for an initial time $X_{0}$, a logistic curve describing the growth kinetics for the exponential phase is obtained (Equation (4)):

$$
X=\frac{X_{0} e^{k t}}{1-\frac{X_{0}}{X_{\infty}}\left(1-e^{k t}\right)}
$$

In batch fermentation experiments, the absence of time-dependent parameters is very useful, since once the parameters $X_{0}, X_{\max }$, and $\mu_{\max }$ are given, and growth can be simulated as a function of time only [26]. All the growth parameters of the kinetic model were fitted to experimental data by nonlinear regression analysis using MATLAB $^{\circledR}$ (The Mathworks, Inc., Natick, MA, USA).

\subsection{Biofilm Separation and Purification}

Based on previously used methodologies [29], the culture broth was centrifuged at $3000 \mathrm{~g}$ for $15 \mathrm{~min}$ at $4{ }^{\circ} \mathrm{C}$, the cell pellet was discarded, and the cell-free supernatant was treated with ethanol for biofilm precipitation. Three volumes of $99.5 \%$ ethanol were 
added to the supernatant, and the mixture was stored overnight at $4{ }^{\circ} \mathrm{C}$ in bottles to allow precipitation of the extracellular polymer. Subsequently, the mixture was centrifuged at $12,500 \mathrm{~g}$ at $4{ }^{\circ} \mathrm{C}$ for $25 \mathrm{~min}$. The supernatant was discarded, and the pellet was transferred to a 50-mL Falcon tube. After that, the tube with the pellet was frozen at $-20^{\circ} \mathrm{C}$, and then freeze-dried for $24 \mathrm{~h}$. For removal of residual peptides, the powder was dissolved in $10 \%(v / v)$ trichloroacetic acid (TCA) solution $(3 \mathrm{~mL})$, left to stand for $30 \mathrm{~min}$, and then centrifuged at $2400 \mathrm{~g}$ and $4{ }^{\circ} \mathrm{C}$ for $15 \mathrm{~min}$. The pellet was then discarded, and the supernatant was frozen and immediately freeze-dried. The final product, which is a white granulated powder, was quantified gravimetrically.

\subsection{Analyses}

Cell growth was determined by measuring the cell dry weight (CDW) of each of the taken samples. Shortly after being collected, cultivation samples were centrifuged in an $\mathrm{N}-2200$ microcentrifuge (MRC-Laboratory Equipment Ltd., Holon, Israel) at $7800 \mathrm{~g}$ for $5 \mathrm{~min}$. The supernatant was separated and stored for HPLC analysis, while the pellet was re-suspended in a sterile $\mathrm{NaCl}$ solution $(0.9 \% w / v)$ and centrifuged again at $7800 \mathrm{~g}$ for $5 \mathrm{~min}$. After discarding the supernatant, the pellet was dried until constant weight at $105^{\circ} \mathrm{C}$ in an SNB 400 oven (Memmert $\mathrm{GmbH}$, Schwabach, Germany), and the CDW was determined gravimetrically.

Before HPLC analysis, aliquots of $500 \mu \mathrm{L}$ of each liquid sample were centrifuged at $16,848 \mathrm{~g}$ for $5 \mathrm{~min}$, and the supernatant was diluted with $4500 \mu \mathrm{L}$ of acidified water (with $\mathrm{H}_{2} \mathrm{SO}_{4}$ ), vortexed for $10 \mathrm{~s}$, and filtered through a 20- $\mu \mathrm{m}$ filter into an HPLC vial. Sugars (glucose, arabinose and xylose) and residual ethanol were separated on an Aminex HPX-87H column (Bio-Rad, Hercules, CA, USA) using as mobile phase $\mathrm{H}_{2} \mathrm{SO}_{4}(5 \mathrm{mM})$ flowing at $0.6 \mathrm{~mL} \mathrm{~min}^{-1}$ and at $60^{\circ} \mathrm{C}$. The analysis was run in a Prominence HPLC system (Shimadzu Corp., Kyoto, Japan) equipped with a system controller CBM-20A, an isocratic pump (LC-30AD), a refraction index detector (RID-20A), an oven column (CTO-10 ASVP), a degasifier (DGU-20A) and an autosampler (SIL-30AC). The injection volume was $20 \mu \mathrm{L}$, and the analyses were carried out in duplicate.

Soluble protein was determined by the Biuret method and Alkali Copper ReagentACR. Bovine Serum Albumin was used as calibration standard, and the absorbance was read at $540 \mathrm{~nm}$ in a Varioskan LUX multimode microplate reader (Thermo Fisher Scientific, Waltham, MA, USA). Nitrogen content in the conditioned RBY supernatant was determined by the Kjeldahl method, as previously reported [30].

\subsection{Fourier-Transform Infrared Spectroscopy (FTIR)}

FTIR was carried out in a Nicolet 6700 (Thermo Fisher Scientific, Waltham, MA, USA) instrument. Samples of dried biofilm (100 mg) were scanned between 500 and $4000 \mathrm{~cm}^{-1}$ to identify the most representative peaks.

\subsection{Scanning Electron Microscopy (SEM)}

SEM was performed with a scanning electron microscope JSM-5900 LV (JEOL, Tokyo, Japan), at a voltage of $10-20 \mathrm{kV}$, and pressure of $10^{4} \mathrm{~Pa}$. Prior to the analysis, a biofilm sample was mixed with water until a homogeneous solution was obtained, and a second sample was analyzed directly without solubilizing it in water. Samples were spread over carbon paper for the analysis.

\subsection{Thermogravimetric Analysis (TGA)}

For the Thermo Gravimetric Analysis, 654-mg samples were processed with a TGAQ500 analyzer (Thermal Analysis Instruments, New Castle, DE, USA). The inner chamber was conditioned with nitrogen, and the heating ramp was set at $10^{\circ} \mathrm{C} \mathrm{min}-1$ until $1000{ }^{\circ} \mathrm{C}$. The thermal treatment was adjusted depending on the mass variation measured by the detector. 


\section{Results}

\subsection{Biomass and Biofilm Production}

The quick acclimatization revealed that RBY was an appropriate substrate for $C$. maltosa SM4 cultivation, as can be seen by the active growth that started since the very beginning of the cultivation (Figure 1). The carbon sources contained in the substrate were enough for supporting the yeast growth without the addition of external sugars. The good cultivation performance also revealed that no nutrient supplementation of the medium was required for $C$. maltosa growth, since the conditioned RBY supernatant was already rich in nutrients resulting from the lysis of brewer's yeast. It is apparent that during the thermal inactivation of residual S. cerevisiae, as part of the RBY conditioning, cell breakdown occurred, and that led to leakage of intracellular components that can serve as nutrients for C. maltose. For example, it is apparent that the quantified nitrogen in the RBY supernatant ( $3.8 \mathrm{~g} \mathrm{~L}^{-1}$ ) was high enough to make it unnecessary to supplement the medium with external nitrogen sources. The biomass production ranged between $13.17 \mathrm{~g} \mathrm{~L}^{-1}$, for the experimental run with $1 \mathrm{~L} \mathrm{~min}^{-1}$ of air flow and $200 \mathrm{rpm}$ agitation, and $16.97 \mathrm{~g} \mathrm{~L}^{-1}$ for $3 \mathrm{~L} \mathrm{~min}^{-1}$ and $100 \mathrm{rpm}$, which corresponded to yields of, respectively, 0.41 and $0.53 \mathrm{~g} \mathrm{~g}^{-1}$ (Table 1). The growth kinetics is shown in Figure 1. A logistic model was applied to predict the growth of $C$. maltosa in the exponential phase. A high degree of agreement between the predicted growth and the actual biomass measured throughout the bioprocess was observed. In the case of the extracellular biofilm produced, for $1 \mathrm{~L} \mathrm{~min}^{-1}$ of air flow, with $200 \mathrm{rpm}$ of agitation, the production was on average $2.33 \mathrm{~g} \mathrm{~L}^{-1}$, and for $3 \mathrm{~L} \mathrm{~min}^{-1}$ of air flow, with $100 \mathrm{rpm}$ of agitation, it averaged $2.20 \mathrm{~g} \mathrm{~L}^{-1}$. Detailed information on the cultivation for different conditions is presented in Table 1.

The carbon source consumption is shown in Figure 2. Ethanol was the preferred substrate. Its consumption started at the beginning of the cultivation, and during the first $24 \mathrm{~h}$ more than $40 \%$ of the initial amount (from 17.2 to $10.1 \mathrm{~g} \mathrm{~L}^{-1}$ ) was consumed. Glucose, xylose and arabinose were used at a low rate. The consumption of all three sugars was only around $5 \%$ during the first $24 \mathrm{~h}$. Although this result was rather surprising, growth of C. maltosa on ethanol has been reported previously. Protein content remained roughly constant during the cultivation process (Data not shown).

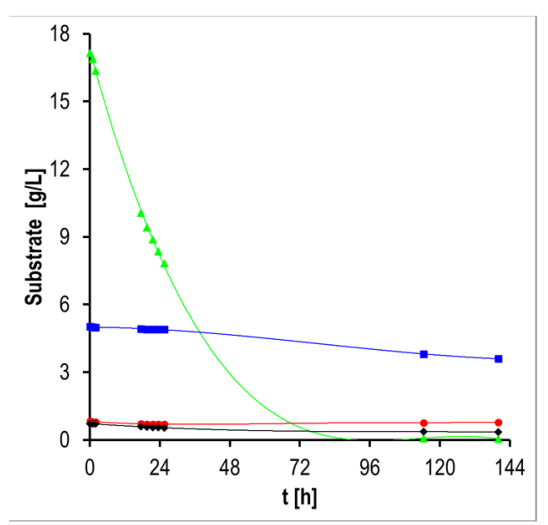

Figure 2. Substrate consumption by C. maltosa SM4 on RBY for $200 \mathrm{rpm}, 1 \mathrm{~L}$ air $\mathrm{min}^{-1}$ : Ethanol ( $\left.\Delta\right)$, Glucose $(\square)$, Xylose $(\bullet)$ and arabinose $(\bullet)$.

\subsection{Effect of Aeration and Agitation on Biomass and Biofilm Production}

Through the use of the Design Expert software, the influence of air inflow and agitation on the growth rate and biofilm production was determined, and the response surfaces are displayed in Figure 3. For biofilm production, increasing the air inflow at low agitation speed resulted in a positive response, while under stronger agitation, an increased aeration led to a negative response (Figure 3a). On the other hand, the agitation speed did not remarkably affect extracellular biofilm production at high aeration, but it resulted in a strong increase at low air inflows. The highest biofilm production was achieved under 
$200 \mathrm{rpm}$ and $1 \mathrm{~L} \mathrm{~min}{ }^{-1}$ of air inflow. As shown by the Pareto chart of standardized effects (Figure 4a), the agitation speed exerted the strongest effect for biofilm production.

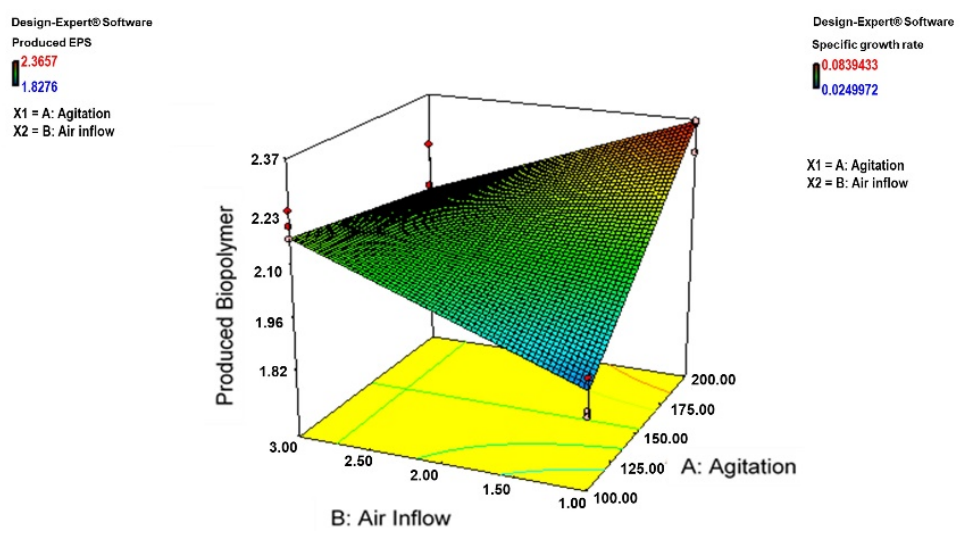

(a)

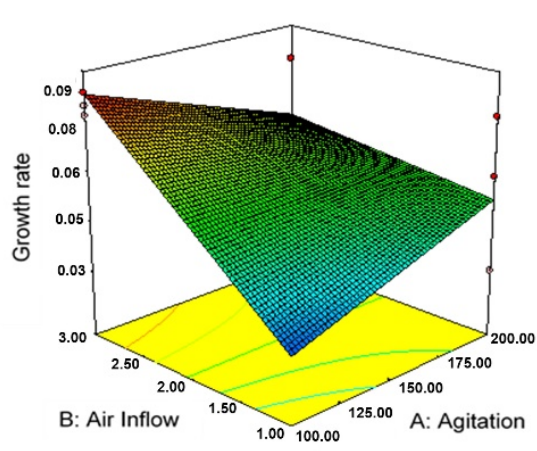

(b)

Figure 3. Interactions of agitation and air inflow over biofilm production (a) and growth rate (b).

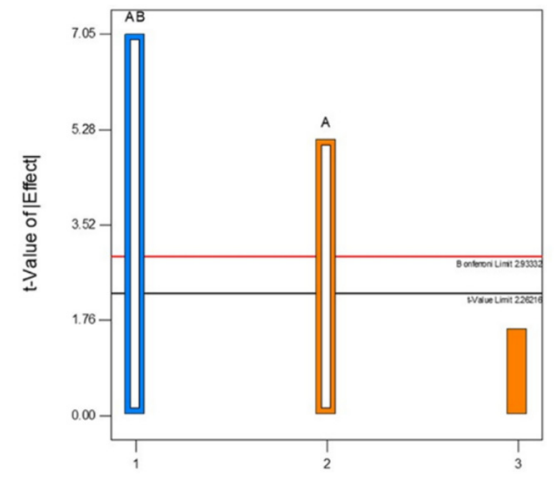

(a)

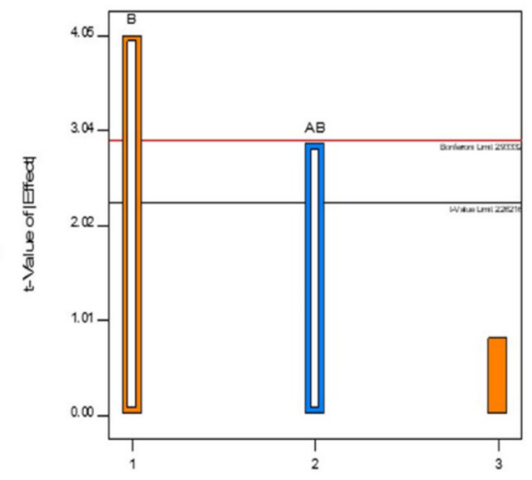

(b)

Figure 4. Pareto charts of standardized effects for biofilm production (a) and growth rate (b); A is agitation and $\mathrm{B}$ is aeration.

The yeast growth rate increased with the increase in the aeration, especially when the cultivation was performed under a low agitation speed (Figure 3b). At the same time, the agitation speed resulted in directly proportional influence on the growth rate only under low air inflow. The highest biomass production was achieved under an aeration of $3 \mathrm{~L} \mathrm{~min}^{-1}$ and an agitation of $100 \mathrm{rpm}$. The air inflow was the variable exerting the strongest effect (Figure $4 b$ ).

\subsection{Characterization of the Biofilm}

\subsubsection{SEM}

SEM was used as a tool for characterization of the produced biofilms. SMS imaging of the purified biofilm resulting from the cultivation at $200 \mathrm{rpm}$ and $1 \mathrm{~L} \mathrm{~min}^{-1}$ reveals a clear tendency towards the formation of films, as inferred from the smooth and continuous surface and structural integrity (Figure 5). Images taken at different magnifications confirmed the film-like pattern of the obtained product. The continuous and glittering surface and the compact structure observed have a similar appearance as that of other previously described microbial biofilms [31,32], and it is different from the rather grainy and discontinuous texture revealed by SMS imaging of non-film forming biopolymers [29]. 
(a)

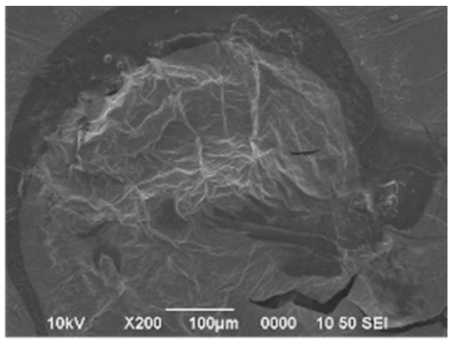

(b)

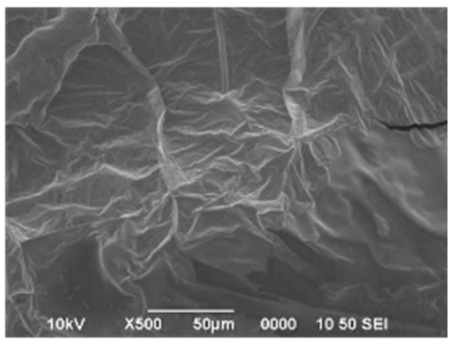

(c)

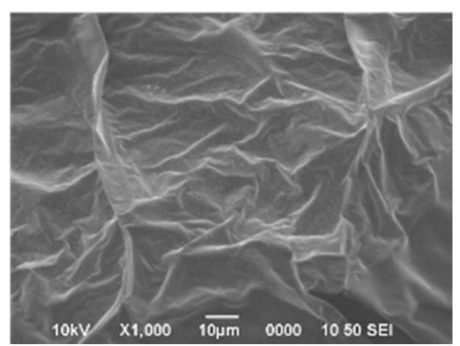

Figure 5. SEM image of the biofilm produced by cultivation of C. maltosa SM4 at $200 \mathrm{rpm}$ and $1 \mathrm{~L}$ $\min ^{-1}$ at (a) $200 \times$, (b) $500 \times$, and (c) $1000 \times$.

\subsubsection{FTIR}

FTIR spectroscopy was another method used for characterization of the produced biofilms, and the spectrum of the sample obtained by cultivation under aeration of $3 \mathrm{~L} \mathrm{~min}^{-1}$ and agitation of $200 \mathrm{rpm}$ is shown in Figure 6. The FTIR spectrum revealed several peaks that point towards a possible carbohydrate. The peak at $2870.8 \mathrm{~cm}^{-1}$ corresponds to the stretching vibration of C-H bonds of methyl groups, as well as in methanetriyl groups (carbon atoms with four different single bonds) typical of carbohydrates [33,34], while the signal at $1431.2 \mathrm{~cm}^{-1}$ can be assigned to symmetric stretching of the C-O bond in carboxylate groups [35]. The peak at $1234.1 \mathrm{~cm}^{-1}$ can be associated with antisymmetric stretching vibrations of the $\mathrm{S}=\mathrm{O}$ bonds in $\mathrm{O}$-sulfate groups of sulfated polysaccharides $[35,36]$. The signal at $1170 \mathrm{~cm}^{-1}$ is characteristic of uronic acid moieties or acetyl esters in polysaccharides [37,38]. Considering the indications pointing at the biofilm being a polysaccharide, it is more likely that this peak corresponds to uronic acid-related vibrations. The peak at $981.8 \mathrm{~cm}^{-1}$ is typical for carbohydrates and it is originated from ring vibrations and asymmetric -C-O-C- stretch in polysaccharides [33], while that at $684.1 \mathrm{~cm}^{-1}$ has previously been attributed to glycosidic linkages between individual glycosil residues in some microbial exopolysaccharides [38]. 


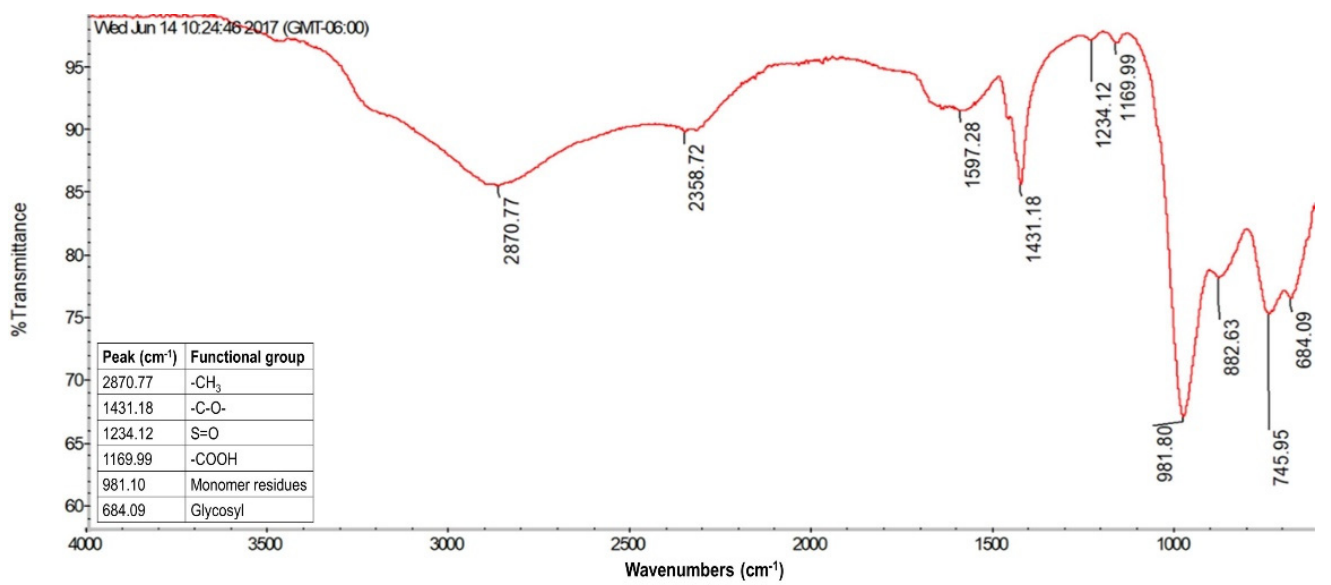

Figure 6. FTIR of biofilm produced by cultivation of C. maltosa SM4 under aeration of $3 \mathrm{~L} \mathrm{~min}^{-1}$ and agitation speed $200 \mathrm{rpm}$.

\subsubsection{TGA Analysis}

The thermogravimetric analysis, which was carried out by heating the biofilm samples up to $1000{ }^{\circ} \mathrm{C}$ at a rate of $10{ }^{\circ} \mathrm{C} \mathrm{min}-1$, revealed the first weight loss between 70 and $169.6^{\circ} \mathrm{C}$ (Figure 7). That loss corresponded to a weight reduction of $47.6 \%$, and it can be explained as water loss of the compound via desorption because of the breakdown of superficial hydrogen bonds.

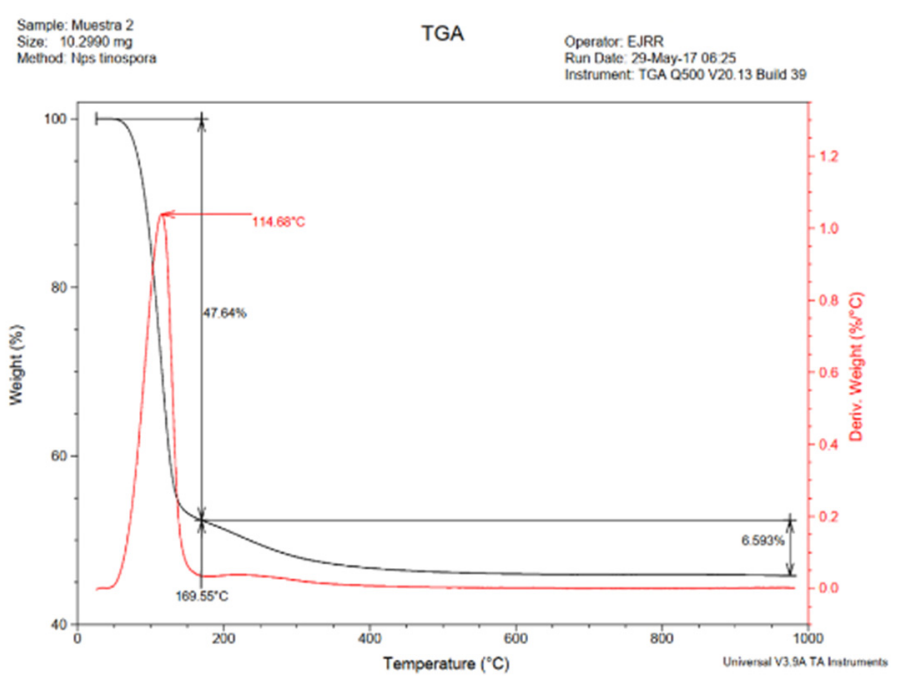

Figure 7. Thermogravimetric (black line) and derivative thermogravimetric (red line) curves resulting from the TGA analysis of the biofilm produced by C. maltosa SM4 cultivation at $200 \mathrm{rpm}$ and $1 \mathrm{~L} \mathrm{~min}^{-1}$.

A second and final weight loss, between 169.6 and $1000{ }^{\circ} \mathrm{C}$, was of the order of $6.6 \%$, and it is associated with the disintegration phase or pyrolysis. No evidence of reconfiguration of morphological structures to more stable configuration, as reported previously for other biofilms/biopolymers [39] were revealed by the TGA of the analyzed sample. The derivative thermogravimetric curve shows that the largest weight reduction rate was observed at $114.68{ }^{\circ} \mathrm{C}$ in the first stage. Since this temperature is rather high, it may suggest that the produced biofilm has a somehow high thermal stability, mainly regarding water retention, and therefore, high potential for gel formation. 


\section{Discussion}

\subsection{Biomass and Biofilm Production}

The potential of C. maltosa as a biofilm producer, as well as a source of microbial biomass, was investigated. Both products are of high interest in the biotechnological industry. Production of single cell protein from different byproducts generated by food industries has extensively been studied as part of efforts for an integral use of bioresources with expected economic potential $[40,41]$. By investigating C. maltosa cultivation on RBY, the current research provides fundamental information for extending the substrate base for SCP production and for valorization of an important brewery residue. This study is in line with previous research on SCP production by cultivation of Candida spp. in substrates based on waste streams of different activities. Candida spp. have previously been investigated as a potential biomass producer that can be cultivated in different residual materials, such as fruit waste, vegetal oils, and even lignocellulosic residues [42-44].

Our results show that the wet brewery waste known as RBY can be used as a substrate for C. maltosa cultivation, resulting in high yields of SCP (as yeast biomass) and biofilm. These results are of high relevance considering that the amount of produced biomass $\left(16.97 \mathrm{~g} \mathrm{~L}^{-1}\right)$ using that industrial waste as a substrate was considerably higher than the values reported for Candida spp. using synthetic media (between 4 and $7 \mathrm{~g} \mathrm{~L}^{-1}$ ) [14], and that no nutrient supplementation was required since the conditioned RBY supernatant already contained the required nutrients, including a high nitrogen content, for supporting C. maltosa growth. Furthermore, the biofilm production achieved in our experiments (2.33 $\mathrm{g} \mathrm{L}^{-1}$ ) compares favorably with that reported for C. famata and C. guilliermondii on synthetic carbon sources $\left(0.7-2.1 \mathrm{~g} \mathrm{~L}^{-1}\right)$ [14]. By showing the potential of RBY for producing SCP and biofilm, we are expanding the utilization possibilities of brewery residues since most previous studies on biotechnological utilization of byproducts of the brewing industry have been centered mostly on brewer's spent grain (BSG), for instance, for producing xylitol, polyhydroxybutyrate [45], and xylooligosaccharides [21]. The results of this study open other utilization possibilities of brewing industry residues. For instance, the combination of RBY with BSG hydrolysates could result in media with the nutrient richness of RBY and the carbon richness of BSG hydrolysates, which would allow achieving higher biomass production than as achieved in this work. On the other hand, since simultaneous production of cell biomass and biopolymers have mostly been based on using bacteria [46], producing them using C. maltosa grown in RBY has clear novelty.

It is also noteworthy that cultivations reported in the current study were based on carbon sources that are different from conventional ones. Typically, carbohydrate-based substrates are used, whereas in the present research, residual ethanol was the main carbon source utilized during cultivation. Although ethanol utilization by yeasts is not a very commonly discussed issue, our result is in line with previously reported growth of $C$. maltosa and other yeasts on ethanol $[47,48]$. Detailed studies on the metabolism of ethanol [49] and other alcohols [50] in C. maltose have been reported, and two different pathways depending on the chain length of the assimilable alcohol have been identified [50]. The ability of $C$. maltosa to grow on a variety of carbon sources is well-known [4]. For instance, the capacity of $C$. maltosa for degrading hydrocarbons, such as phenylalkanes and $n$-alkanes, has been exploited for bioremediation after accidental oil spills [6,7]. Furthermore, its efficient utilization of furfural and 5-hydroxymethylfurfural, which are known inhibitors of microbial growth [51], allowed its use as a detoxifying agent in a study on xylitol production by recombinant Bacillus subtilis using a xylose-rich liquor as substrate [52]. Although the initial ethanol concentration $\left(16.9 \mathrm{~g} \mathrm{~L}^{-1}\right)$ in the current study might have been challenging, the growth of C. maltose was not surprising since other yeasts of the Candida genus have also been shown to grow well on comparable or even higher ethanol levels. For instance, initial ethanol concentrations of $16-32 \mathrm{~g} \mathrm{~L}^{-1}$ were reported in C. utilis cultivation for producing metabolites [53], and high resistance to ethanol concentrations of up to $25 \%(v / v)$ has been shown for C. stellata [54]. 
The biotechnological utilization of by-products generated by food-oriented industries requires their conditioning for making them amenable as substrate by producing microorganisms of relevance. In the current investigation, a simple procedure including baker's yeast inactivation at $90^{\circ} \mathrm{C}$ and separation of the solid phase by centrifugation was enough for allowing microbial growth in RBY supernatant. That is different from other residual materials, which require more sophisticated strategies to assure substrate fermentability [55]. The yield of targeted bioproducts from potential substrates can be further maximized through the use of software simulation tools. In this work, that was achieved using the statistical software Design Expert. For broader criteria analyses of brewery residues-based biorefineries, alternative software like Aspen Plus ${ }^{\circledR}$ can be used [20].

\subsection{Logistic Approach for Modeling the Cell Growth}

The logistic approach has been thoroughly used for bioprocesses when no timedependent parameters such as substrate concentration are available, and it is possible instead to solve it as a function of time [26]. That simplifies data analysis and avoids the trouble of simultaneous solution methods [56]. The logistic growth equation can be used instead of the rather complicated Monod kinetics to describe batch microbial growth at relatively low substrate concentrations. Moreover, in order to make better approximations to the bioprocesses themselves, using as few measurable parameters as possible usually results in better described-and modelled-systems [26].

Fermentation processes can in general be well described by the logistic approach [57]. As it was shown in Figure 1, using the logistic approach in this study allowed modeling the cell growth of C. maltosa in RBY in an accurate way, with good agreement between the predicted growth and the actual biomass measured throughout the bioprocess. This can be useful in future experiments considering the requirement of preliminary modeling of many bioprocesses, especially those performed on a larger scale than lab bench tests.

\subsection{Effect of Aeration and Agitation on Biomass and Biofilm Production}

The identification of aeration and agitation speed as controlling variables agrees well with the literature referred to the production of extracellular biopolymers through microbial fermentation [58-60]. Moreover, the strong effect of aeration on production of C. maltosa SM4 biomass is in agreement with previous reports on other Candida species [61,62]. It can be explained by the fact that both aeration and agitation increase the amount of dissolved oxygen and help to disperse nutrients and other substances in the medium, which results in higher microbial growth, and thus, more cell biomass formation. The ranges tested for both independent variables, which were set based on the available equipment, resulted in easily differentiable results, which provide reproducible conditions and valuable information for future research.

\subsection{Characterization of the Biofilm and Preliminary Evaluation of Potential Applications}

SEM imaging of the produced biofilm revealed a continuous film-like shape, which was evident at different magnifications. The clearly distinguishable continuous surface can be an indication of film-forming potential [63]. FTIR analysis revealed the presence of methyl, sulfate and uronic acid groups, all of which are good indicators of a wide spectrum of potential applications for the extracellular biofilm [33,35]. FTIR also gave indications about the possible carbohydrate nature of the produced biofilm. The TGA revealed a rather high resistance to thermal degradation, which hints at a potential for gel formation.

From the characterization through different techniques, the film-forming ability of the product, which is indeed a biofilm, was confirmed, and its high thermal stability, and gel-formation capacity can be inferred [32]. Such characteristics are desirable traits for applications, especially in the food industry sector [64]. The presence of the sulfate groups revealed by the FTIR spectra of the biofilm can anticipate possible medical applications [65]. 


\subsection{Modeling As A Tool for Optimizing Bioconversion of Brewery Residues}

Modeling tools are of paramount importance for bioprocess engineering, since they can provide exact and reproducible guidelines based on a thorough analysis of process data $[26,66]$. Application of modeling to the results of bioconversion of RBY reported in this study helps to optimize the target products, as in previous studies with other brewery residues $[67,68]$. Bioprocessing of waste streams of the brewing industry is an attractive emerging sector, whose possibilities can be potentiated provided that the involved processes are properly optimized [69-71]. Accurate description and simulation of bioprocesses using mathematical models based on lab-scale results are crucial for their industrial-scale implementation with minimal economic affectations [56,72].

In the current study, a high degree of agreement was found between the cell growth trend predicted by the model and the actual experimental measurements for C. maltosa biomass production. Applying the same model in larger-scale experiments would avoid costly media misformulations and other unnecessary expenses, and it would allow maximizing the product yields with a rational utilization of resources. This investigation not only proposes a feasible strategy for adding value to an underutilized brewery waste, but it also shows a way for optimizing the production of the end-products, cell biomass and biofilm, through statistical modeling. Furthermore, the performed characterization enables a preliminary screening of potential application of the produced biofilm.

\section{Conclusions}

The results of the current study highlight the importance of using industrial wastes to obtain high added-value products through microbial fermentation. The feasibility of producing biofilm and cell biomass by C. maltosa cultivation using the liquid fraction of residual brewing yeast as substrate was demonstrated. C. maltosa SM4 proved to be capable of utilizing the carbon sources available in RBY for producing biomass and biofilm at higher yields than those achieved by other members of the Candida spp. grown on synthetic carbon sources. Aeration and agitation were pinpointed as key operational variables for biomass and biofilm production by C. maltosa SM4 cultivation in RBY. Production of biomass and biofilm were affected in different ways by the variation of the independent factors, and operational conditions leading to maximal production of both of them were identified.

Author Contributions: Conceptualization, C.C. and L.R.-S.; methodology, C.C., V.F.-C., L.R.-S. and C.M.; formal analysis, C.C., L.R.-S., V.F.-C.; investigation, V.F.-C., L.R.-S., D.R.-C., F.O.-G. and J.V-B.; resources, C.C., M.T.A.-A. and C.M.; writing-original draft preparation, L.R.-S.; writing-review and editing, C.C., C.M., M.T.A.-A., D.R.-C., F.O.-G. and J.V.-B.; visualization, L.R.-S.; supervision, C.C. and M.T.A.-A.; project administration, C.C. and C.M.; funding acquisition, C.C. and C.M. All authors have read and agreed to the published version of the manuscript.

Funding: This research was funded by SIDA (Swedish International Development Cooperation Agency) and the Swedish Research Council (2016-05822) for financial support.

Institutional Review Board Statement: Not applicable.

Informed Consent Statement: Not applicable.

Acknowledgments: The technical support provided by all researchers and staff from the Industrial Biotechnology division from the Faculty of Pharmaceutics and Biochemistry in Bolivia is greatly appreciated.

Conflicts of Interest: The authors declare no conflict of interest. The funders had no role in the design of the study; in the interpretation of data; in the writing of the manuscript, or in the decision to publish the results. 


\section{References}

1. Byerlee, D.; Fanzo, J. The SDG of zero hunger 75 years on: Turning full circle on agriculture and nutrition. Glob. Food Sec. 2019, 21, 52-59. [CrossRef]

2. Renneberg, R.; Berkling, V.; Loroch, V. Green Biotechnology. In Biotechnology for Beginners, 2nd ed.; Renneberg, R., Berkling, V., Loroch, V., Eds.; Academic Press: New York, NY, USA, 2017; pp. 233-279.

3. Roth, F.X. Microorganisms as a source of protein for animal nutrition. In Advances in Agricultural Microbiology, 1st ed.; Subba Rao, N.S., Ed.; Butterworth-Heinemann Ltd.: Oxford, UK, 1982.

4. Wolf, K. Nonconventional Yeasts in Biotechnology; Springer: Berlin/Heidelberg, Germany, 1996.

5. Komagata, K.; Nakase, T.; Katsuya, N. Assimilation of hydrocarbons by yeast. I. Preliminary screening. J. Gen. Appl. Microbiol. 1964, 10, 313-321. [CrossRef]

6. Awe, S.; Mikolasch, A.; Hammer, E.; Schauer, F. Degradation of phenylalkanes and characterization of aromatic intermediates acting as growth inhibiting substances in hydrocarbon utilizing yeast Candida maltosa. Int. Biodeter. Biodegrad. 2008, 62, 408-414. [CrossRef]

7. Dmitriev, V.V.; Crowley, D.; Rogachevsky, V.V.; Negri, C.M.; Rusakova, T.G.; Kolesnikova, S.A.; Akhmetov, L.I. Microorganisms form exocellular structures, trophosomes, to facilitate biodegradation of oil in aqueous media. FEMS Microbiol. Lett. 2011, 315, 134-140. [CrossRef]

8. Chrzanowski, Ł.; Kaczorek, E.; Olszanowski, A. The ability of Candida maltosa for hydrocarbon and emulsified hydrocarbon degradation. Pol. J. Environ. Stud. 2006, 47-51.

9. Echenique, P. Screening y Selección de Microorganismos que Posean Fuerte Capacidad de Formación de un Biofilm Estable en Condiciones Optimizadas de Cultivo. Bachelor's Thesis, Universidad Mayor de San Andrés, La Paz, Bolivia, 2013.

10. Romero, D.X.; Cárdenas, O.V.; Álvarez, M.T. Detection of ALS3 and EAP1 gene expression in Candida albicans and Candida maltosa biofilms by FISH. J. Adv. Biotechnol. 2016, 6, 848-857. [CrossRef]

11. Singh, R.; Paul, D.; Jain, R.K. Implications in bioremediation. Trends Microbiol. 2006, 14, 389-397. [CrossRef]

12. Nicolella, C.; Van Loosdrecht, M.C.M.; Heijnen, J.J. Wastewater treatment with particulate biofilm reactors. J. Biotechnol. 2000, 80, 1-33. [CrossRef]

13. Williams, P.A. (Ed.) Renewable Resources for Functional Polymers and Biomaterials: Polysaccharides, Proteins and Polyesters, 1st ed.; Polymer Chemistry Series; RSC Publishing: London, UK, 2011.

14. Gientka, I.; Bzducha-Wróbel, A.; Stasiak-Różańska, L.; Bednarska, A.A.; Błażejak, S. The exopolysaccharides biosynthesis by Candida yeast depends on carbon sources. Electron. J. Biotechnol. 2016, 22, 31-37. [CrossRef]

15. Cheng, K.C.; Demirci, A.; Catchmark, J.M. Pullulan: Biosynthesis, production, and applications. Appl. Microbiol. Biotechnol. 2011, 92, 29-44. [CrossRef] [PubMed]

16. Martins, C.D.C.; De Aguiar, P.F.; Sérvulo, E.F.C. Production of Bacillus sphaericus entomopathogenic biomass using brewery residues. Appl. Biochem. Biotechnol. 2006, 131, 659-667. [CrossRef]

17. Brochier, M.A.; Carvalho, S. Aspectos ambientais, produtivos e econômicos do aproveitamento de resíduo úmido de cervejaria na alimentação de cordeiros em sistema de confinamento (Environmental, productive and economic aspects of use of brewery residue as food of lamb feedlots in finishing phase). Ciência Agrotecnologia 2009, 33, 1392-1399. (In Portuguese)

18. Butt, K.R. Utilisation of solid paper-mill sludge and spent brewery yeast as a feed for soil-dwelling earthworms. Bioresour. Technol. 1993, 44, 105-107. [CrossRef]

19. Gonçalves, G.D.C.; Nakamura, P.K.; Furtado, D.F.; Veit, M.T. Utilization of brewery residues to produces granular activated carbon and bio-oil. J. Clean. Prod. 2017, 168, 908-916. [CrossRef]

20. Mussatto, S.I.; Moncada, J.; Roberto, I.C.; Cardona, C.A. Techno-economic analysis for brewer's spent grains use on a biorefinery concept: The Brazilian case. Bioresour. Technol. 2013, 148, 302-310. [CrossRef]

21. González-García, S.; Morales, P.C.; Gullón, B. Estimating the environmental impacts of a brewery waste-based biorefinery: Bio-ethanol and xylooligosaccharides joint production case study. Ind. Crops Prod. 2018, 123, 331-340. [CrossRef]

22. Mathias, T.R.S.; de Mello, P.P.M.; Sérvulo, E.F.C. Solid wastes in brewing process: A review. J. Brew. Distill. $2014,5,1-9$.

23. Ivanova, V.; Antontceva, E.; Harbah, R.; Meledina, T.; Shamtsyan, M. Residual brewing yeasts as a source of beta-glucans. E3S Web Conf. 2020, 164, 06027. [CrossRef]

24. Rashid, N.F.M.; Azemi, M.A.F.M.; Amirul, A.A.A.; Wahid, M.; Bhubalan, K. Simultaneous production of biopolymer and biosurfactant by genetically modified Pseudomonas aeruginosa UMTKB-5. IPCBEE 2015, 90, 16-21.

25. Soto, L.R.; Byrne, E.; van Niel, E.W.; Sayed, M.; Carrasco, C.; Hatti-Kaul, R. Hydrogen and polyhydroxybutyrate production from wheat straw hydrolysate using Caldicellulosiruptor species and Ralstonia eutropha in a coupled process. Bioresour. Technol. 2019, 272, 259-266. [CrossRef]

26. Shuler, M.L.; Karg1, F.; DeLisa, M. Bioprocess Engineering: Basic Concepts, 3rd ed.; Prentice Hall: Hoboken, NJ, USA, 2017.

27. Wang, D.; Xu, Y.; Hu, J.; Zhao, G. Fermentation kinetics of different sugars by apple wine yeast Saccharomyces cerevisiae. J. Inst. Brew. 2004, 110, 340-346. [CrossRef]

28. Sivarathnakumar, S.; Jayamuthunagai, J.; Baskar, G.; Praveenkumar, R.; Aberna Ebenezer Selvakumari, I.; Bharathiraja, B. Bioethanol production from woody stem Prosopis juliflora using thermotolerant yeast Kluyveromyces marxianus and its kinetics studies. Bioresour. Technol. 2019, 293, 122060. [CrossRef] 
29. Chambi, D.; Romero-Soto, L.; Villca, R.; Orozco-Gutierrez, F.; Vega-Baudrit, H.; Quillaguamán, J.; Hatti-Kaul, R.; Martín, C.; Carrasco, C. Exopolysaccharides production by cultivating a bacterial isolate from the hypersaline environment of Salar de Uyuni (Bolivia) in pretreatment liquids of steam-exploded quinoa stalks and enzymatic hydrolyzates of Curupaú sawdust. Fermentation 2021, 7, 33. [CrossRef]

30. Bremner, J. Determination of nitrogen in soil by the Kjeldahl method. J. Agric. Sci. 1960, 55, 11-33. [CrossRef]

31. Ahmed, Z.; Wang, Y.; Anjum, N.; Ahmad, A.; Khan, S.T. Characterization of exopolysaccharide produced by Lactobacillus kefiranofaciens ZW3 isolated from Tibet kefir-Part II. Food Hydrocoll. 2013, 30, 343-350. [CrossRef]

32. Asahi, Y.; Miura, J.; Tsuda, T.; Kuwabata, S.; Tsunashima, K.; Noiri, Y.; Hayashi, M. Simple observation of Streptococcus mutans biofilm by scanning electron microscopy using ionic liquids. AMB Express 2015, 5, 1-9. [CrossRef]

33. Kielak, A.; Castellane, T.; Campanharo, J.; Colnago, L.; Costa, O.; Silva, M.; van Veen, J.; Lemos, E.; Kuramae, E. Characterization of novel Acidobacteria exopolysaccharides with potential industrial and ecological applications. Sci. Rep. 2016, 7, 41193. [CrossRef]

34. Tipson, R.S. Infrared Spectroscopy of Carbohydrates: A Review of the Literature. NBS Monograph; United States Government Printing Office: Washington, DC, USA, 1968.

35. Barros, F.; Silva, D.; Sombra, V.; Maciel, J.; Feitosa, J.; Freitas, A.; de Paula, R. Structural characterization of polysaccharide obtained from red seaweed Gracilaria caudata (J Agardh). Carbohydr. Polym. 2013, 92, 598-603. [CrossRef] [PubMed]

36. Hussein, M.; Abou-ElWafa, G.; Shaaban-Dessuuki, S.; Hassan, N. Characterization and antioxidant activity of exopolysaccharide secreted by Nostoc carneum. Int. J. Pharmacol. 2015, 11, 432-439. [CrossRef]

37. Mahmood, W.; Khan, M.; Yee, T. Effects of reaction temperature on the synthesis and thermal properties of carrageenan ester. $J$. Phys. Sci. 2014, 25, 123-138.

38. Rani, R.; Anadharaj, M.; Sabhapathy, P.; Ravindran, A. Physiochemical and biological characterization of novel exopolysaccharide produced by Bacillus tequilensis FR9 isolated from chicken. Int. J. Biol. Macromol. 2016, 96, 1-10. [CrossRef]

39. Daoub, R.; Elmurabak, A.; Misran, M.; Hassan, E.; Osman, M. Characterization and functional properties of some natural Acacia gums. J. Saudi Soc. Agric. Sci. 2016, 17, 241-249. [CrossRef]

40. Sindhu, R.; Gnansounou, E.; Rebello, S.; Binod, P.; Varjani, S.; Thakur, I.S.; Pandey, A. Conversion of food and kitchen waste to value-added products. J Environ. Manag. 2019, 241, 619-630. [CrossRef]

41. Moreno, A.D.; Ballesteros, M.; Negro, M.J. Biorefineries for the valorization of food processing waste. In The Interaction of Food Industry and Environment; Galanakis, C., Ed.; Academic Press: New York, NY, USA, 2020; pp. 155-190.

42. Munawar, R.A.; Irfan, M.; Nadeem, M.; Syed, Q.A.; Siddique, Z.H. Biosynthesis of single cell biomass of Candida utilis by submerged fermentation. Pak. J. Sc. 2010, 62, 1-5.

43. Begea, M.; Sirbu, A.; Kourkoutas, Y.; Dima, R. Single-cell protein production of Candida strains in culture media based on vegetal oils. Rom. Biotechnol. Lett. 2012, 17, 7776-7786.

44. Yunus, F.U.N.; Nadeem, M.; Rashid, F. Single-cell protein production through microbial conversion of lignocellulosic residue (wheat bran) for animal feed. J. Inst. Brew. 2015, 121, 553-557. [CrossRef]

45. Dávila, J.A.; Rosenberg, M.; Cardona, C.A. A biorefinery approach for the production of xylitol, ethanol and polyhydroxybutyrate from brewer's spent grain. AIMS Agric. Food 2016, 1, 52-66. [CrossRef]

46. Giavasis, I.; Robertson, I.; McNeil, B.; Harvey, L.M. Simultaneous and rapid monitoring of biomass and biopolymer production by Sphingomonas paucimobilis using Fourier transform-near infrared spectroscopy. Biotechnol. Lett. 2003, 25, 975-979. [CrossRef] [PubMed]

47. Minkevich, I.G.; Baumann, F.; Rogge, G.; Heinritz, B. Ratio of heat production to oxygen consumption during the cell cycle of Candida maltosa EH 15 grown on ethanol. Acta Biotechnol. 1988, 8, 435-444. [CrossRef]

48. Kometani, T.; Morita, Y.; Kiyama, Y.; Yoshii, H.; Matsuno, R. Relationship between ethanol consumption rate and prochiral ketone reduction rate in bakers' yeast. J. Ferm. Bioeng. 1995, 80, 208-210. [CrossRef]

49. Hofmann, K.H.; Polnisch, E. Activities of gluconeogenetic enzymes in the yeast Candida maltosa during growth on glucose or ethanol. J. Basic Microbiol. 1990, 30, 333-336. [CrossRef] [PubMed]

50. Sharyshev, A.A.; Peskova, E.B.; Komarova, G.N.; Blinova, T.V. Subcellular organization of aliphatic alcohol metabolism in the yeast Candida maltosa. Appl. Biochem. Microbiol. 1996, 32, 111-118.

51. Jönsson, L.J.; Martín, C. Pretreatment of lignocellulose: Formation of inhibitory by-products and strategies for minimizing their effects. Bioresour. Technol. 2016, 199, 103-112. [CrossRef] [PubMed]

52. Cheng, H.; Wang, B.; Lv, J.; Jiang, M.G.; Lin, S.J.; Deng, Z.X. Xylitol production from xylose mother liquor: A novel strategy that combines the use of recombinant Bacillus subtilis and Candida maltosa. Microb. Cell Factories 2011, 10, 1-12. [CrossRef]

53. Domenech, F.; Christen, P.; Paca, J.; Revah, S. Ethanol utilization for metabolite production by Candida utilis strains in liquid medium. Acta Biotechnol. 1999, 19, 27-36. [CrossRef]

54. Pina, C.; Santos, C.; Couto, J.A.; Hogg, T. Ethanol tolerance of five non-Saccharomyces wine yeasts in comparison with a strain of Saccharomyces cerevisiae - Influence of different culture conditions. Food Microbiol. 2004, 21, 439-447. [CrossRef]

55. Outeiriño, D.; Costa-Trigo, I.; de Souza Oliveira, R.P.; Guerra, N.P.; Domínguez, J.M. A novel approach to the biorefinery of brewery spent grain. Proc. Biochem. 2019, 85, 135-142. [CrossRef]

56. Narayanan, H.; Luna, M.F.; von Stosch, M.; Cruz Bournazou, M.N.; Polotti, G.; Morbidelli, M.; Butté, A.; Sokolov, M. Bioprocessing in the digital age: The role of process models. Biotechnol. J. 2020, 15, 1900172. [CrossRef] 
57. Jakymec, M.; Morán, H.; Páez, G.; Ferrer, J.; Mármol, Z.; Ramones, E. Kinetic of the Lactic Acid Production by Submerged Fermentation whit Whey as Substrate. Rev. Científica-Fac. Cienc. Vet. 2001, 11, 53-59.

58. Bandaiphet, C.; Prasertsan, P. Effect of aeration and agitation rates and scale-up on oxygen transfer coefficient, kLa in exopolysaccharide production from Enterobacter cloacae WD7. Carbohydr. Polym. 2006, 66, 216-228. [CrossRef]

59. Giavasis, I.; Harvey, L.M.; McNeil, B. The effect of agitation and aeration on the synthesis and molecular weight of gellan in batch cultures of Sphingomonas paucimobilis. Enz. Microb. Technol. 2006, 38, 101-108. [CrossRef]

60. Radchenkova, N.; Vassilev, S.; Martinov, M.; Kuncheva, M.; Panchev, I.; Vlaev, S.; Kambourova, M. Optimization of the aeration and agitation speed of Aeribacillus palidus 418 exopolysaccharide production and the emulsifying properties of the product. Proc. Biochem. 2014, 49, 576-582. [CrossRef]

61. Rosma, A.; Ooi, K.I. Production of Candida utilis biomass and intracellular protein content: Effect of agitation speed and aeration rate. Malays. J. Microb. 2006, 2, 15-18. [CrossRef]

62. Dimova, N.D.; Iovkova, Z.S.; Brinkova, M.; Godjevargova, T.I. Production of Candida biomass from hydrolysed agricultural biowaste. Biotechnol. Biotechnol. Equip. 2010, 24, 1577-1581. [CrossRef]

63. Zakeri, A.; Pazouki, M.; Vossougi, M. Development of kinetic model for xanthan production in a laboratory-scale batch fermentor. Iran. J. Sci. Technol. Trans. Sci. 2018, 42, 261-266. [CrossRef]

64. Khan, T.; Park, J.K.; Kwon, J.H. Functional biopolymers produced by biochemical technology considering applications in food engineering. Korean J. Chem. Eng. 2007, 24, 816-826. [CrossRef]

65. de Jesus Raposo, M.F.; de Morais, A.M.M.B.; de Morais, R.M.S.C. Influence of sulphate on the composition and antibacterial and antiviral properties of the exopolysaccharide from Porphyridium cruentum. Life Sci. 2014, 101, 56-63. [CrossRef]

66. Cutlip, M.B.; Shacham, M. Problem solving in chemical and biochemical engineering with POLYMATH, Excel, and MATLAB. In Reference Module in Chemistry, Molecular Sciences and Chemical Engineering, 2nd ed.; Prentice Hall: Hoboken, NJ, USA, 2008; pp. $1-17$.

67. Rana, S.S.; Janveja, C.; Soni, S.K. Brewer's spent grain as a valuable substrate for low cost production of fungal cellulases by statistical modeling in solid state fermentation and generation of cellulosic ethanol. Int. J. Food Ferment. Technol. 2013, 3, 41-55. [CrossRef]

68. Carciochi, R.A.; Sologubik, C.A.; Fernández, M.B.; Manrique, G.D.; D'Alessandro, L.G. Extraction of antioxidant phenolic compounds from brewer's spent grain: Optimization and kinetics modeling. Antioxidants 2018, 7, 45. [CrossRef] [PubMed]

69. Sharma, B.; Ingalls, R.G.; Jones, C.L.; Huhnke, R.L.; Khanchi, A. Scenario optimization modeling approach for design and management of biomass-to-biorefinery supply chain system. Bioresour. Technol. 2013, 150, 163-171. [CrossRef]

70. Sanz, A.; Susmozas, A.; Peters, J.; Dufour, J. Biorefinery modeling and optimization. In Biorefineries. Lecture Notes in Energy; Rabaçal, M., Ferreira, A., Silva, C., Costa, M., Eds.; Springer: Cham, Switzerland, 2017; Volume 57, pp. 123-160.

71. Ploch, T.; Zhao, X.; Hüser, J.; von Lieres, E.; Hannemann-Tamás, R.; Naumann, U.; Wiechert, W.; Mitsos, A.; Noack, S. Multiscale dynamic modeling and simulation of a biorefinery. Biotechnol. Bioeng. 2019, 116, 2561-2574. [CrossRef] [PubMed]

72. Spann, R.; Lantz, A.E.; Gernaey, K.V.; Sin, G. Modeling for process risk assessment in industrial bioprocesses. In Reference Module in Chemistry, Molecular Sciences and Chemical Engineering; Elsevier: Amsterdam, The Netherlands, 2018; pp. 1-17. 